\title{
Serum anion gap, bicarbonate and biomarkers of inflammation in healthy individuals in a national survey
}

\author{
Wildon R. Farwell MD MPH, Eric N. Taylor MD MSc
}

Previously published at www.cmaj.ca

\section{ABSTRACT}

Background: In vitro data suggest that lower extracellular $\mathrm{pH}$ activates the immune system. We conducted a population-based study of the relation between serum acid-base status and inflammation.

Methods: We examined the serum anion gap and serum levels of bicarbonate and inflammatory biomarkers in 4525 healthy adults who participated in the National Health and Nutrition Examination Survey during 19992006. We excluded participants who had chronic disease, recent infection and an estimated glomerular filtration rate of less than $60 \mathrm{~mL} / \mathrm{min}$ per $1.73 \mathrm{~m}^{2}$.

Results: The mean values of serum anion gap, bicarbonate level, leukocyte count and C-reactive protein level were all within normal limits. After adjustment for age, sex, ethnic background, body mass index, serum albumin level and other factors, we found that a higher anion gap and lower bicarbonate level were associated with a higher leukocyte count and higher C-reactive protein level. Compared with participants in the lowest quartile of anion gap, those in the highest quartile had a leukocyte count that was $1.0 \times$ $10 \%$ higher and a C-reactive protein level that was $10.9 \mathrm{nmol} / \mathrm{L}$ higher $(p<0.01)$. Compared with participants in the highest quartile of bicarbonate level, those in the lowest quartile had a leukocyte count that was $0.7 \times 10 \% / \mathrm{L}$ higher and a C-reactive protein level that was $4.0 \mathrm{nmol} / \mathrm{L}$ higher $(p \leq 0.02)$. A higher anion gap and lower bicarbonate level were also associated with a higher platelet count, a larger mean platelet volume and a higher ferritin level.

Interpretation: A higher serum anion gap and lower bicarbonate level were associated with higher levels of inflammatory biomarkers in a healthy sample of the general population. Further studies are needed to elucidate the relation between acid-base status and inflammation.

$\mathrm{H}$ igher levels of inflammatory biomarkers are associated with increased mortality and the development of chronic disease. A recent study reported that allcause mortality increased $11 \%$ for every increase of $1.0 \times$ $10^{9} / \mathrm{L}$ in leukocyte count above $3.5 \times 10^{9} / \mathrm{L} .^{1}$ Other studies also reported a significant relation between mortality and markers of inflammation. ${ }^{2}$ A higher leukocyte count, Creactive protein level and mean platelet volume predict the development of cardiovascular disease and cancer. ${ }^{3-5}$
Despite the importance of low-grade inflammation in the pathogenesis of chronic disease, factors influencing inflammation in apparently healthy individuals are not well delineated. In vitro data suggest that extracellular $\mathrm{pH}$ may modulate inflammation. Trevani and colleagues reported that neutrophils were less active at a $\mathrm{pH}$ of 7.4 than at a lower $\mathrm{pH}$. Lower extracellular $\mathrm{pH}$ also appeared to increase neutrophil production and delay neutrophil apoptosis. Additional studies have shown that lower extracellular $\mathrm{pH}$ activates other components of the immune system, including other immune cells and the complement system. ${ }^{8}$

Existing studies linking acidosis to inflammation have generally examined the impact of acute large reductions in extracellular $\mathrm{pH}$. However, chronic small reductions in $\mathrm{pH}$ affect a variety of physiologic processes and may have a substantial impact on inflammation and the development of chronic disease. ${ }^{9}$ For example, we previously reported that small increases in serum anion gap and small decreases in bicarbonate levels in healthy individuals whose acid-base parameters were within normal limits were associated with elevated blood pressure and increased insulin resistance, ${ }^{10,11}$ independent of body size and kidney function.

We conducted a population-based study of the relation between serum acid-base status and inflammation. We examined the association between serum anion gap and serum levels of bicarbonate and inflammatory biomarkers in healthy individuals who participated in the National Health and Nutrition Examination Survey during 1999-2006.

\section{Methods}

\section{Study population}

We obtained data for individuals who participated in the National Health and Nutrition Examination Survey in 1999/ 2000, 2001/02, 2003/04 or 2005/06. The design of the survey has been described previously. ${ }^{12}$ In brief, the survey provides nationally representative cross-sectional data on the health status of the general population of the United States. Participants

From the Massachusetts Veterans Epidemiology Research and Information Center, VA Boston Healthcare System, and the Division of Aging, Department of Medicine, Brigham and Women's Hospital, Harvard Medical School (Farwell); and the Renal Division and Channing Laboratory, Department of Medicine, Brigham and Women's Hospital, Harvard Medical School (Taylor), Boston, USA

CMAJ 2009. DOI:10.1503/cmaj.090329 
were interviewed and underwent physical examination. Participants over the age of 12 years who did not have hemophilia or undergo recent cancer chemotherapy were eligible for venipuncture.

For our analysis, we excluded participants who had acute or chronic diseases that could potentially affect their serum acid-base status and inflammatory biomarker levels. From an initial cohort of 22624 participants aged 18 years or more, we excluded 12877 who had self-reported chronic disease, including arthritis, diabetes mellitus, hypertension, chronic kidney disease, congestive heart failure, coronary artery disease, myocardial infarction, angina, cerebrovascular disease, liver disease and cancer (except nonmelanoma skin cancer). We also excluded 1144 participants who were taking oral hypoglycemic therapy, insulin, antihypertensive therapy, diuretics, cholesterol-lowering medications, nonsteroidal antiinflammatory drugs or acetylsalicylic acid; 1983 participants who reported having an infection within the month before the survey; 301 participants who reported donating blood within the year before the survey; 935 participants without dietary information; and 507 participants without laboratory information. We excluded an additional 309 participants who had an albumin level of less than $35 \mathrm{~g} / \mathrm{L}$, a calcium level of more than $2.6 \mathrm{mmol} / \mathrm{L}$ or an estimated glomerular filtration rate of less than $60 \mathrm{~mL} / \mathrm{min}$ per $1.73 \mathrm{~m}^{2}$. Finally, to eliminate outliers, we excluded 43 participants who had extreme values for serum anion gap. We included the remaining 4525 participants in our analysis.

\section{Measurement of laboratory parameters}

Serum levels of electrolytes, albumin and creatinine were measured with the use of a Hitachi Model 704 multichannel analyzer (Boehringer Mannheim Diagnostics, Indianapolis, USA) and the Beckman Synchron LX20 (Beckman Coulter Inc., Fullerton, USA). We calculated the anion gap according to the following equation: anion gap $(\mathrm{mmol} / \mathrm{L})=$ serum sodium level $(\mathrm{mmol} / \mathrm{L})$ - $[$ serum chloride level $(\mathrm{mmol} / \mathrm{L})+$ serum bicarbonate level $(\mathrm{mmol} / \mathrm{L})]$.

Leukocyte counts, platelet counts and mean platelet volume were measured with the use of a Beckman Coulter MAXM Analyzer (Beckman Coulter Inc.). C-reactive protein levels were measured with the use of a Dad Behring Nephelometer II Analyzer System (Dad Behring Diagnostics Inc., Somerville, USA). Serum ferritin levels were measured with the use of the Quantimune Ferritin IRMA kit (Bio-Rad Laboratories, Hercules, USA). Fibrinogen levels were measured by means of the Clauss clotting method on the STA-Compact analyzer (Diagnostica Stago S.A., Asnieres, France). Serum ferritin and fibrinogen levels were not available for individuals who participated in the 2003/04 and 2005/06 surveys.

We calculated the glomerular filtration rate according to the simplified prediction equation in the Modification of Diet in Renal Disease Study (MDRD). ${ }^{13}$ We corrected serum creatinine levels for participants in the 1999/2000 and 2005/06 surveys to align creatinine values with the creatinine assay used in the development of the MDRD equation. ${ }^{14,15}$ Serum creatinine levels for participants in the 2001/02 and 2003/04 surveys did not require correction.

\section{Statistical analysis}

Because older individuals, Hispanic and black individuals were intentionally overrepresented in the survey populations, we applied appropriate sample weights to obtain weighted regression estimates. The final results of our analyses are generalizable to the US population.

We divided values for serum anion gap into quartiles. Within each quartile, we calculated the percentage of each categorical demographic characteristic and the mean (and standard error) of age, body mass index (BMI) and each laboratory measurement. Ethnic background was predefined in the surveys as non-Hispanic white, non-Hispanic black, Hispanic or other. In linear regression analyses, we included leukocyte count, neutrophil count, lymphocyte count, monocyte count, eosinophil count, basophil count, C-reactive protein level, platelet count, mean platelet volume, ferritin level and fibrinogen level as dependent variables, with quartiles of serum anion gap (or continuous anion gap) as the independent variable. We considered the following covariates: age, sex, ethnic background, use of alcohol, BMI, dietary protein intake, and serum levels of creatinine, albumin, urea, uric acid and cotinine. We calculated 95\% confidence intervals (CIs) for parameter estimates of the dependent variables. We calculated tests of trend across quartiles of anion gap values, with the median value of each quartile serving as an ordinal variable. All $p$ values were 2 -sided. We performed similar analyses with serum bicarbonate level, rather than anion gap, as the independent variable.

Protocols to recruit and examine participants of the National Health and Nutrition Examination Surveys were reviewed and approved by the US National Center for Health Statistics Institutional Review Board.

\section{Results}

The following mean values were all within normal limits: serum anion gap $11.6 \mathrm{mmol} / \mathrm{L}$, bicarbonate level $24.2 \mathrm{mmol} / \mathrm{L}$, leukocyte count $7.2 \times 10^{9} / \mathrm{L}$, C-reactive protein level $26.0 \mathrm{nmol} / \mathrm{L}$, platelet count $271.6 \times 10^{9} / \mathrm{L}$, mean platelet volume $8.2 \mathrm{fL}$, ferritin level $261.7 \mathrm{pmol} / \mathrm{L}$ and fibrinogen level $10.1 \mu \mathrm{mol} / \mathrm{L}$. Characteristics of the 4525 participants included in our study, by quartile of serum anion gap, are shown in Table 1 . The different numbers of participants in each quartile were a result of the high frequency of shared anion gap levels in our population. Because the associations between serum anion gap and biomarkers of inflammation and between serum bicarbonate level and biomarkers of inflammation did not vary by sex or race, we combined results for men and women and for different ethnic groups.

Serum anion gap was positively associated with leukocyte count and C-reactive protein level (Table 2). After multivariable adjustment (for age, sex, BMI, ethnic background, use of alcohol, dietary protein intake, and serum levels of creatinine, albumin, urea, uric acid and cotinine), we found that the leukocyte count increased by $1.5(95 \%$ CI $1.2-1.9) \times 10^{\circ} / \mathrm{L}$ and the C-reactive protein level by 1.8 (95\% CI $1.2-2.5) \mathrm{nmol} / \mathrm{L}$ for every increase of $1 \mathrm{mmol} / \mathrm{L}$ in anion gap. The $R^{2}$ for the multivariable-adjusted models was 0.15 for the leukocyte count and 0.21 for the C-reactive protein level. After multivariable adjustment, participants in the highest quartile of anion gap, com- 
pared with those in the lowest quartile, had a leukocyte count that was $1.0 \times 10^{9} / \mathrm{L}$ higher $(p$ for trend $<0.01$ ) and a C-reactive protein level $10.9 \mathrm{nmol} / \mathrm{L}$ higher $(p$ for trend $<0.01$ ).

Serum anion gap was also positively associated with platelet count, mean platelet volume and ferritin level. After multivariable adjustment, participants in the highest quartile of anion gap, compared with those in the lowest quartile, had a platelet count that was $12.5 \times 10^{\circ} / \mathrm{L}$ higher $(p$ for trend $<0.01$ ), a mean platelet volume $0.2 \mathrm{fL}$ higher $(p$ for trend $<0.01$ ) and a ferritin level $8.9 \mathrm{pmol} / \mathrm{L}$ higher $(p$ for trend $=0.05$ ).

We found an inverse relation between serum bicarbonate level and inflammatory biomarkers. After multivariable adjustment, the leukocyte count increased by $0.1(95 \%$ CI $0.06-0.2) \times$ $10 \% / \mathrm{L}$ and the C-reactive protein level by 0.6 (95\% CI 0.0-1.1) $\mathrm{nmol} / \mathrm{L}$ for every decrease of $1 \mathrm{mmol} / \mathrm{L}$ in serum bicarbonate level. After multivariable adjustment, participants in the lowest quartile of serum bicarbonate level, compared with those in the highest quartile, had a leukocyte count that was $0.7 \times 10^{9} / \mathrm{L}$ higher $(p$ for trend $<0.01)$ and a C-reactive protein level that was $4.0 \mathrm{nmol} / \mathrm{L}$ higher $(p$ for trend $=0.02)($ Table 3$)$.

Serum bicarbonate level was also inversely associated with platelet count, mean platelet volume and ferritin level. After multivariable adjustment, participants in the lowest quartile of serum bicarbonate level, compared with those in the highest quartile, had a platelet count that was $12.5 \times 10^{9} / \mathrm{L}$ higher ( $p$ for trend $<0.01$ ), a mean platelet volume that was $0.2 \mathrm{fL}$ higher $(p$ for trend $=0.02$ ) and a ferritin level that was $49.9 \mathrm{pmol} / \mathrm{L}$ higher $(p$ for trend $<0.01$ ).

After multivariable adjustment, both a higher serum anion gap and a lower serum bicarbonate level were associated with higher neutrophil, lymphocyte and monocyte counts $(p<0.01)$. Only a higher anion gap was also associated with a higher

Table 1: Characteristics of 4525 healthy adults who participated in the National Health and Nutrition Examination Survey during 1999-2006, by quartile of serum anion gap

\begin{tabular}{|c|c|c|c|c|}
\hline \multirow[b]{2}{*}{ Characteristic } & \multicolumn{4}{|c|}{ Quartile of serum anion gap } \\
\hline & $\begin{array}{c}\text { Quartile 1 } \\
(<10 \mathrm{mmol} / \mathrm{L}) \\
n=856\end{array}$ & $\begin{array}{c}\text { Quartile 2 } \\
\text { (10-11 mmol/L) } \\
n=1499\end{array}$ & $\begin{array}{c}\text { Quartile 3 } \\
\text { (12-13 mmol/L) } \\
n=1203\end{array}$ & $\begin{array}{c}\text { Quartile } 4 \\
\text { (> } 13 \mathrm{mmol} / \mathrm{L}) \\
n=967\end{array}$ \\
\hline Serum anion gap, mmol/L, mean (SE) & $8.5(0.0)$ & $10.5 \quad(0.0)$ & $12.5(0.0)$ & $15.1(0.1)$ \\
\hline Serum bicarbonate level, mmol/L, mean (SE) & $25.4(0.1)$ & $24.7 \quad(0.1)$ & $23.8(0.1)$ & $22.9 \quad(0.2)$ \\
\hline Age, yr, mean (SE) & $38.2(0.6)$ & $37.5(0.4)$ & $38.0(0.4)$ & $36.5(0.5)$ \\
\hline Sex, female, $\%$ of participants & 53.2 & 48.9 & 48.1 & 43.4 \\
\hline \multicolumn{5}{|l|}{ Ethnic background, \% of participants } \\
\hline Non-Hispanic white & 67.0 & 66.2 & 66.6 & 69.2 \\
\hline Non-Hispanic black & 14.3 & 12.4 & 11.0 & 8.5 \\
\hline Hispanic & 14.1 & 15.7 & 16.8 & 19.1 \\
\hline Other & 4.5 & 5.7 & 5.6 & 3.1 \\
\hline \multicolumn{5}{|l|}{ Use of alcohol, \% of participants } \\
\hline Weekly & 30.4 & 31.5 & 30.6 & 35.1 \\
\hline Monthly & 20.5 & 20.0 & 19.8 & 19.4 \\
\hline Yearly & 17.5 & 20.4 & 20.9 & 18.8 \\
\hline Never & 31.6 & 28.1 & 28.8 & 26.8 \\
\hline Body mass index, mean (SE) & $26.6(0.2)$ & $27.1 \quad(0.2)$ & $26.5(0.2)$ & $26.9(0.2)$ \\
\hline Serum cotinine level, nmol/L, mean (SE) & $332.5(23.2)$ & $372.3(24.7)$ & 404.7 (31.3) & $389.5(40.3)$ \\
\hline Serum albumin, g/L, mean (SE) & $42.8 \quad(0.2)$ & $43.5 \quad(0.1)$ & $44.4 \quad(0.2)$ & $45.3 \quad(0.2)$ \\
\hline Serum creatinine, $\mu \mathrm{mol} / \mathrm{L}$, mean (SE) & $64.2(0.6)$ & $64.9(0.5)$ & $65.6(0.6)$ & $66.5(0.5)$ \\
\hline Serum uric acid, $\mu \mathrm{mol} / \mathrm{L}$, mean (SE) & $294.5(3.5)$ & $305.0 \quad(3.1)$ & $314.2(3.7)$ & $317.7 \quad(3.0)$ \\
\hline Serum urea, $\mathrm{mmol} / \mathrm{L}$, mean (SE) & $4.1(0.1)$ & $4.2(0.1)$ & $4.4(0.1)$ & $4.7(0.1)$ \\
\hline Dietary protein intake, $\mathrm{g}$, mean (SE) & $88.9(1.9)$ & $90.8 \quad(1.7)$ & $89.6(1.8)$ & $88.3(2.0)$ \\
\hline Leukocyte count, $\times 10^{9} / \mathrm{L}$, mean (SE) & $6.6(0.1)$ & $7.1(0.1)$ & $7.4(0.1)$ & $7.5 \quad(0.1)$ \\
\hline Platelet count, $\times 10^{9} / \mathrm{L}$, mean (SE) & 263.4 (3.2) & $273.1 \quad(2.6)$ & $274.5 \quad(2.2)$ & $273.2(2.7)$ \\
\hline Mean platelet volume, $\mathrm{fL}$, mean (SE) & $8.1 \quad(0.1)$ & $8.1 \quad(0.0)$ & $8.2(0.0)$ & $8.3(0.1)$ \\
\hline C-reactive protein, nmol/L, mean (SE) & $24.4(1.4)$ & 24.5 (1.4) & $27.3(1.6)$ & $28.4 \quad(1.3)$ \\
\hline Ferritin, pmol/L, mean (SE)* & $276.2(30.0)$ & $232.0(12.4)$ & $237.6(9.0)$ & $293.4(14.6)$ \\
\hline Fibrinogen, $g / L$, mean $(S E)^{*}$ & $10.0(0.3)$ & $9.9(0.2)$ & $10.1(0.2)$ & $10.3(0.2)$ \\
\hline
\end{tabular}

Note: $\mathrm{SE}=$ standard error .

*Data are from the $1999 / 2000$ and $2001 / 02$ cohorts only. 
basophil count $(p=0.02)$. Serum anion gap and bicarbonate level were not associated with eosinophil count or fibrinogen level.

The results did not change significantly after further adjustment of multivariable models for serum levels of calcium, potassium and insulin, and dietary potassium intake.

\section{Interpretation}

Among healthy adults who participated in the National Health and Nutrition Examination Survey during 1999-2006, we found that a higher anion gap and a lower serum bicarbonate level were associated with higher levels of several inflammatory biomarkers, including leukocyte count and C-reactive protein level. These relations were independent of age, sex, BMI, ethnic background, use of alcohol, dietary protein intake, and serum levels of creatinine, cotinine, albumin, uric acid and urea. Because we excluded participants who had chronic diseases, those with an estimated glomerular filtration rate of less than $60 \mathrm{~mL} / \mathrm{min}$ per $1.73 \mathrm{~m}^{2}$ and those who were taking a variety of medications, it is unlikely that illness or a reduced glomerular filtration rate accounted for the associations with inflammatory biomarkers. Of note, the mean values of serum electrolytes, leukocyte count, C-reactive protein level, platelet count, mean platelet volume, ferritin level and fibrinogen level in our study population were all within normal limits.

The cause of the observed association between higher serum anion gap and higher levels of inflammatory biomarkers in this apparently healthy population is unknown. Elevations in the serum anion gap can result from an increase in unmeasured anions, as occurs in several forms of metabolic acidosis, or from a decrease in unmeasured cations. ${ }^{16}$ In general, reductions in serum calcium and potassium concentrations are an unusual cause of an increased anion gap. ${ }^{16}$ In our study, the relation between anion gap and inflammation was unchanged after adjustment for these cations. Serum albumin can also affect the anion gap ${ }^{17}$ however, we excluded individuals with low serum albumin levels and adjusted for albumin in the multivariable analyses. A mild increase in anion gap has been reported in metabolic alkalosis $;^{18}$ however, we are unaware of data linking metabolic alkalosis to inflammation. In our study, higher serum bicarbonate levels were not associated with higher levels of inflammatory biomarkers.

Table 2: Adjusted differences in inflammatory biomarkers, by quartile of serum anion gap

\begin{tabular}{|c|c|c|c|c|c|}
\hline \multirow[b]{2}{*}{ Biomarker } & \multicolumn{4}{|c|}{ Quartile of serum anion gap; difference in biomarker $(95 \% \mathrm{Cl})$} & \multirow[b]{2}{*}{$\begin{array}{l}p \text { value } \\
\text { for trend }\end{array}$} \\
\hline & $\begin{array}{c}\text { Quartile 1 } \\
(<10 \mathrm{mmol} / \mathrm{L})\end{array}$ & $\begin{array}{c}\text { Quartile 2 } \\
\text { (10-11 mmol/L) }\end{array}$ & $\begin{array}{c}\text { Quartile } 3 \\
\text { (12-13 mmol/L) }\end{array}$ & $\begin{array}{c}\text { Quartile 4 } \\
\text { (> } 13 \mathrm{mmol} / \mathrm{L})\end{array}$ & \\
\hline \multicolumn{6}{|l|}{ Leukocyte count, $\times 10^{9} / \mathrm{L}$} \\
\hline Adjusted for age & Referent & $0.5 \quad(0.3$ to 0.8$)$ & $0.9 \quad(0.6$ to 1.1$)$ & $1.0(0.7$ to 1.2$)$ & $<0.01$ \\
\hline $\begin{array}{l}\text { Adjusted for multiple } \\
\text { variables* }\end{array}$ & Referent & $0.5 \quad(0.3$ to 0.7$)$ & $0.9 \quad(0.6$ to 1.1$)$ & $1.0(0.7$ to 1.3$)$ & $<0.01$ \\
\hline \multicolumn{6}{|c|}{ C-reactive protein level, $\mathrm{nmol} / \mathrm{L}$} \\
\hline Adjusted for age & Referent & $0.2(-3.6$ to 4.0$)$ & $3.0(-1.5$ to 7.5$)$ & $4.4(0.6$ to 8.1$)$ & 0.01 \\
\hline $\begin{array}{l}\text { Adjusted for multiple } \\
\text { variables* }\end{array}$ & Referent & $1.4(-2.3$ to 5.2$)$ & $7.5 \quad(3.2$ to 11.8$)$ & $10.9(6.2$ to 15.6$)$ & $<0.01$ \\
\hline
\end{tabular}

Note: $\mathrm{Cl}=$ confidence interval.

*Adjusted for age, sex, body mass index, ethnic background, use of alcohol, serum levels of cotinine, albumin, creatinine, uric acid and urea, and dietary protein intake.

Table 3: Adjusted differences in inflammatory biomarkers, by quartile of serum bicarbonate level

\begin{tabular}{|c|c|c|c|c|c|}
\hline \multirow[b]{2}{*}{ Biomarker } & \multicolumn{4}{|c|}{ Quartile of serum bicarbonate level; difference in biomarker $(95 \% \mathrm{Cl})$} & \multirow[b]{2}{*}{$\begin{array}{l}p \text { value } \\
\text { for treno }\end{array}$} \\
\hline & $\begin{array}{c}\text { Quartile } 4 \\
\text { (> } 25 \mathrm{mmol} / \mathrm{L})\end{array}$ & $\begin{array}{c}\text { Quartile 3 } \\
\text { (25 mmol/L) }\end{array}$ & $\begin{array}{c}\text { Quartile 2 } \\
\text { (23-24 mmol/L) }\end{array}$ & $\begin{array}{c}\text { Quartile 1 } \\
(<23 \mathrm{mmol} / \mathrm{L})\end{array}$ & \\
\hline \multicolumn{6}{|l|}{ Leukocyte count, $\times 10^{9} / \mathrm{L}$} \\
\hline Adjusted for age & Referent & $0.3 \quad(0.0$ to 0.4$)$ & $0.7 \quad(0.3$ to 1.0$)$ & $1.0(0.7$ to 1.3$)$ & $<0.01$ \\
\hline $\begin{array}{l}\text { Adjusted for multiple } \\
\text { variables* }\end{array}$ & Referent & $0.1(-0.0$ to 0.3$)$ & $0.4 \quad(0.2$ to 0.6$)$ & $0.7(0.3$ to 1.0$)$ & $<0.01$ \\
\hline \multicolumn{6}{|c|}{ C-reactive protein level, $\mathrm{nmol} / \mathrm{L}$} \\
\hline Adjusted for age & Referent & $5.6 \quad(1.2$ to 10.1$)$ & $8.2 \quad(5.5$ to 11.0$)$ & $15.4(11.4$ to 19.3$)$ & $<0.01$ \\
\hline $\begin{array}{l}\text { Adjusted for multiple } \\
\text { variables* }\end{array}$ & Referent & $1.6(-2.7$ to 6.0$)$ & $2.1(-1.0$ to 5.1$)$ & $4.0 \quad(0.9$ to 7.2$)$ & 0.02 \\
\hline
\end{tabular}


The participants in our study who had a higher anion gap may have had a circulating unmeasured anion that contributed to a greater level of inflammation. The inverse relation between serum bicarbonate and inflammatory biomarkers suggests that such an anion, if present, may be the conjugate base of an organic acid. In vitro data suggest that lower extracellular $\mathrm{pH}$ stimulates the inflammatory response. Lower extracellular $\mathrm{pH}$ results in lower intracellular $\mathrm{pH}$ in neutrophils, ${ }^{6}$ which may activate neutrophils. ${ }^{19}$ Furthermore, lower extracellular $\mathrm{pH}$ may activate the complement system. ${ }^{8}$

The small increases in levels of inflammatory biomarkers associated with increasing anion gap in our study were similar in size to the changes observed in other studies linking inflammation to the development of various chronic diseases. For each increase of $1.0 \times 10^{\circ} / \mathrm{L}$ in leukocyte count, the risk of cardiovascular events among postmenopausal women has been found to increase by $11 \%^{3}$ and the risk of death from any cause in the general population has been found to increase by $11 \%{ }^{1}$ Similar findings have been reported for death secondary to coronary artery disease ${ }^{20}$ cerebrovascular disease ${ }^{21}$ and cancer. ${ }^{22}$ Several studies have shown that the risk of cardiovascular disease increases significantly with increasing levels of Creactive protein. ${ }^{23}$ Erlinger and colleagues found that an increase of $1.02 \mathrm{mg} / \mathrm{L}(9.7 \mathrm{nmol} / \mathrm{L})$ in C-reactive protein level increased the risk of colorectal cancer by $43 \%{ }^{4}$

\section{Limitations}

Our study has limitations. First, because the data were crosssectional, we were unable to determine whether higher serum anion gap or lower serum bicarbonate level were risk factors for, rather than the result of, inflammation. Thus, our observational data are hypothesis generating. Second, unknown factors may have affected both the serum acid-base status and the inflammatory biomarker levels in our study participants. Our multivariable regression models accounted for only $15 \%-21 \%$ of the variation in leukocyte count and C-reactive protein level. Third, the study participants did not eat controlled diets. However, the primary dietary determinants of net endogenous acid production are total protein and potassium. ${ }^{9}$ Adjustment for the intake of these factors did not change our results. Finally, we did not have measurements of arterial $\mathrm{pH}$ or partial pressure of carbon dioxide, nor did we have urinary parameters to measure renal net acid excretion. Thus, we are unable to assess fully the acid-base status of the participants in the study.

\section{Conclusion}

A higher serum anion gap and a lower serum bicarbonate level, despite being within normal limits, were independently associated with higher levels of inflammatory biomarkers in a healthy sample of the general population. These data raise the possibility that increased production of organic acid mediates the chronic inflammatory state that increases the risk of coronary artery disease and cancer. Further studies are needed to determine the effect of alkali supplementation on inflammatory biomarker levels and to examine prospectively the relation between acid-base status, inflammation and chronic disease.

This article has been peer reviewed.
Competing interests: None declared.

Contributors: Both of the authors contributed substantially to the study concept and design. Wildon Farwell was responsible for the acquisition and analysis of the data. Both of the authors interpreted the results, drafted and critically revised the manuscript and approved the final version submitted for publication.

Funding: The study was supported by the US National Institutes of Health (grant no. DK73381). The study sponsor was not involved in the design or conduct of the study, the collection, management, analysis or interpretation of the data, or the preparation, review or approval of the manuscript.

\section{REFERENCES}

1. Ruggiero C, Metter EJ, Cherubini A, et al. White blood cell count and mortality in the Baltimore Longitudinal Study of Aging. J Am Coll Cardiol 2007;49:1841-50.

2. Labry LO, Campion EW, Glynn RJ, et al. White blood cell count as a predictor of mortality: results over 18 years from the normative aging study. $J$ Clin Epidemiol 1990;43:153-7.

3. Margolis KL, Rodabough RJ, Thomson CA, et al. Prospective study of leukocyte count as a predictor of incident breast, colorectal, endometrial, and lung cancer and mortality in postmenopausal women. Arch Intern Med 2007;167:1837-44.

4. Erlinger TP, Platz EA, Rifai N, et al. C-reactive protein and the risk of incident colorectal cancer. JAMA 2004;291:585-90.

5. Bath P, Algert C, Chapman N, et al. Association of mean platelet volume with risk of stroke among 3134 individuals with history of cerebrovascular disease. Stroke 2004;35:622-6.

6. Trevani AS, Andonegui G, Giordano M, et al. Extracellular acidification induces human neutrophil activation. J Immunol 1999;162:4849-57.

7. Martinez D, Vermeulen M, Von Euw E, et al. Extracellular acidosis triggers the maturation of human dendritic cells and the production of IL-12. J Immunol 2007; 179:1950-9.

8. Fishelson Z, Horstmann RD, Muller-Eberhard HJ. Regulation of the alternative pathway of complement by pH. J Immunol 1987;138:3392-5.

9. Frassetto L, Morris RC, Sellmeyer DE, et al. Diet, evolution and aging, the pathophysiologic effects of the post-agricultural inversion of the potassium-to-sodium and base-to-chloride ratios in the human diet. Eur J Nutr 2001;40:200-13.

10. Taylor EN, Forman JP, Farwell WR. Serum anion gap and blood pressure in the National Health and Nutrition Examination Survey. Hypertension 2007;50:320-4.

11. Farwell WR, Taylor EN. Serum bicarbonate, anion gap and insulin resistance in the National Health and Nutrition Examination Survey. Diabet Med 2008;25:798804.

12. National Health and Nutrition Examination Survey, 2007-2008: overview. Hyattsville (MD): US Centers for Disease Control and Prevention; 2007. Available: www.cdc.gov/nchs/data/nhanes/nhanes_07_08/overviewbrochure_0708.pdf (accessed 2009 Nov. 20).

13. National Kidney Foundation. K/DOQI clinical practice guidelines for chronic kidney disese: evaluation, classification, and stratification. Am J Kidney Dis 2002;39:920-9.

14. Coresh J, Astor BC, McQuillan G, et al. Calibration and random variation of the serum creatinine assay as critical elements of using equations to estimate glomerular filtration rate. Am J Kidney Dis 2002;39:920-9.

15. Coresh J, Byrd-Holt D, Astor BC, et al. Chronic kidney disease awareness, prevalence, and trends among U.S. adults, 1999 to 2000. J Am Soc Nephrol 2005;16: $180-8$.

16. Rose BD, Post TW. Clinical physiology of acid-base and electrolyte disorders. 5th ed. New York (NY): McGraw-Hill; 2001.

17. Figge J, Jabor A, Kazda A, et al. Anion gap and hypoalbuminemia. Crit Care Med 1998:26:1807-10.

18. Madias NE, Ayus JC, Adrogue HJ. Increased anion gap in metabolic alkalosis: the role of plasma-protein equivalency. N Engl J Med 1979;300:1421-3.

19. Yuli I, Oplatka A. Cytosolic acidification as an early transductory signal of human neutrophil chemotaxis. Science 1987;235:340-2

20. Margolis KL, Manson JE, Greenland P, et al. Leukocyte count as a predictor of cardiovascular events and mortality in postmenopausal women: the Women's Health Initiative Observational Study. Arch Intern Med 2005;165:500-8.

21. Brown DW, Ford ES, Giles WH, et al. Associations between white blood cell count and risk for cerebrovascular disease mortality: NHANES II Mortality Study, 1976-1992. Ann Epidemiol 2004;14:425-30.

22. Erlinger TP, Muntner P, Helzlsouer KJ. WBC count and the risk of cancer mortality in a national sample of U.S. adults: results from the Second National Health and Nutrition Examination Survey mortality study. Cancer Epidemiol Biomarkers Prev 2004;13:1052-6.

23. Ridker PM, Cushman M, Stampfer MJ, et al. Inflammation, aspirin, and the risk of cardiovascular disease in apparently healthy men. N Engl J Med 1997;336:973-9.

Correspondence to: Dr. Wildon R. Farwell, Massachusetts Veterans Epidemiology Research and Information Center (MAVERIC), VA Boston Healthcare System, 150 S Huntington Ave., Boston MA

02130,USA; wildon.farwell@va.gov 